\title{
Nonlinear finite element analysis of grouted and ungrouted hollow interlocking mortarless block masonry system
}

\begin{abstract}
The main feature of the interlocking hollow block masonry is the replacement of mortar layers commonly used in bonded masonry with interlocking keys (protrusions and grooves). This study covers the modelling and the analysis of interlocking mortarless ungrouted (hollow) and grouted concrete block system subjected to axial compression loads using FEM. The main features simulated in the developed finite element code are the mechanical characteristics of the interlocking dry joints including the geometric imperfection of the shell beds of the blocks, the interaction between block units, the progressive debonding between the block and grout and material nonlinearity. The applicability of the proposed FE model is investigated by demonstrating the nonlinear structural response and failure mechanism of individual block, ungrouted and grouted interlocking mortarless prisms. The results found show good agreement with the experimental test results.
\end{abstract}

Keyword: Finite element method, Nonlinear analysis, Constitutive relations, Interlocking masonry block, Modelling of dry joint, Geometric imperfection, Block-grout bond 